\title{
Evaluation of Additive Manufacturing for Composite Part Molds
}

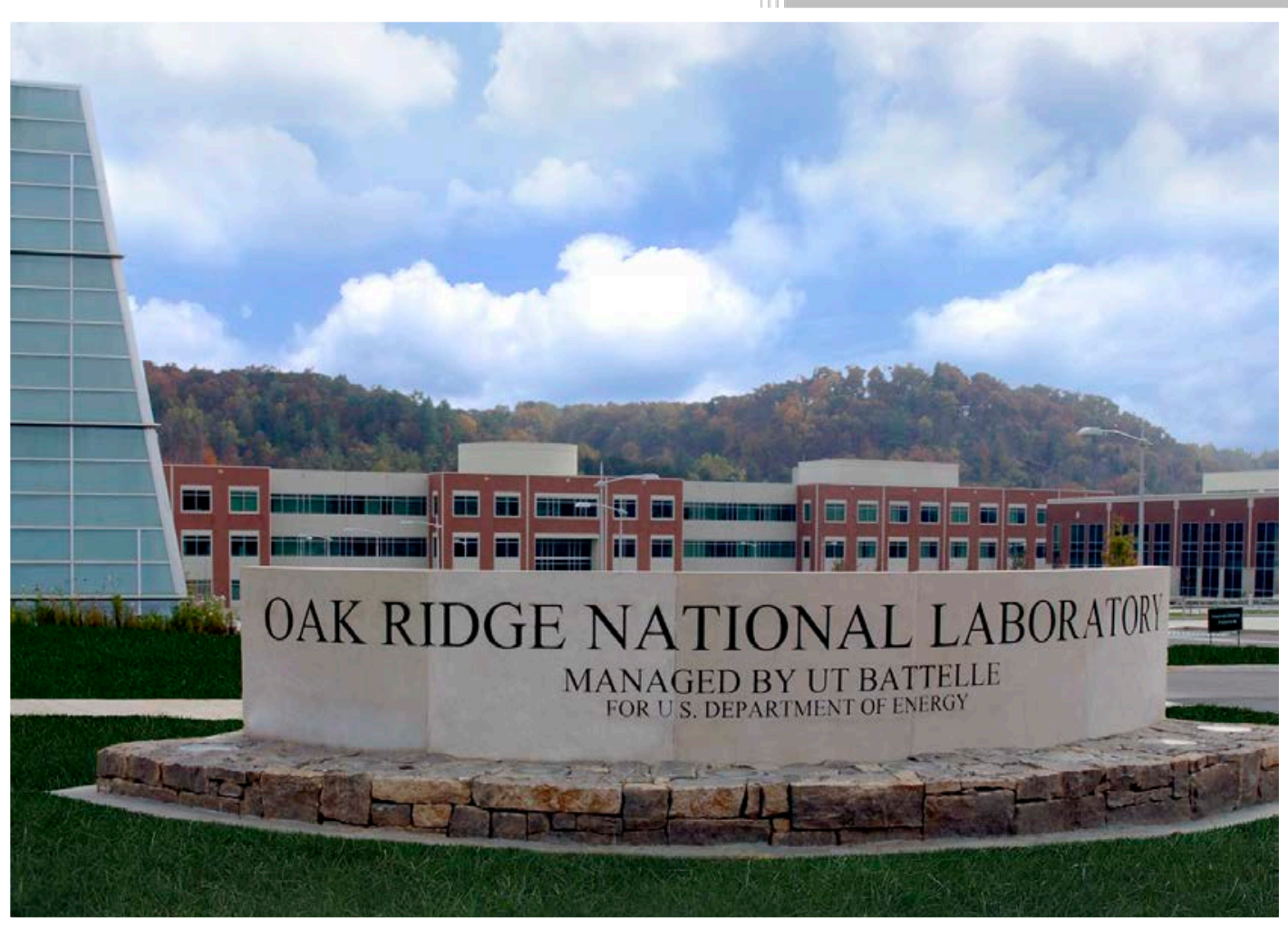

FINAL CRADA REPORT NFE-14-05107

Approved for Public Release. Distribution is Unlimited. 


\title{
DOCUMENT AVAILABILITY
}

Reports produced after January 1, 1996, are generally available free via US Department of Energy (DOE) SciTech Connect.

Website http://www.osti.gov/scitech/

Reports produced before January 1, 1996, may be purchased by members of the public from the following source:

\author{
National Technical Information Service \\ 5285 Port Royal Road \\ Springfield, VA 22161 \\ Telephone 703-605-6000 (1-800-553-6847) \\ TDD 703-487-4639 \\ Fax 703-605-6900 \\ E-mail info@ntis.gov \\ Website http://www.ntis.gov/help/ordermethods.aspx
}

Reports are available to DOE employees, DOE contractors, Energy Technology Data Exchange representatives, and International Nuclear Information System representatives from the following source:

Office of Scientific and Technical Information

PO Box 62

Oak Ridge, TN 37831

Telephone 865-576-8401

Fax 865-576-5728

E-mail reports@osti.gov

Website http://www.osti.gov/contact.html

This report was prepared as an account of work sponsored by an agency of the United States Government. Neither the United States Government nor any agency thereof, nor any of their employees, makes any warranty, express or implied, or assumes any legal liability or responsibility for the accuracy, completeness, or usefulness of any information, apparatus, product, or process disclosed, or represents that its use would not infringe privately owned rights. Reference herein to any specific commercial product, process, or service by trade name, trademark, manufacturer, or otherwise, does not necessarily constitute or imply its endorsement, recommendation, or favoring by the United States Government or any agency thereof. The views and opinions of authors expressed herein do not necessarily state or reflect those of the United States Government or any agency thereof. 
ORNL/TM-2015/96

CRADA/NFE-14-05107

Materials Science and Technology Division Advanced Manufacturing Office

Evaluation of Additive Manufacturing for Composite Part Molds

\author{
Authors \\ Chad Duty \\ Robert Springfield, Tru Design, LLC \\ Date Published: \\ February 24, 2015 \\ Prepared by \\ OAK RIDGE NATIONAL LABORATORY \\ Oak Ridge, Tennessee 37831-6283 \\ managed by \\ UT-BATTELLE, LLC \\ for the \\ US DEPARTMENT OF ENERGY \\ under contract DE-AC05-00OR22725
}

Approved For Public Release 


\title{
Evaluation of Additive Manufacturing for Composite Part Molds ${ }^{1}$
}

\author{
Tru-Design, LLC
}

Project ID:

MDF-TC-2014-042

Start Date:

$05 / 02 / 2014$

Completion Date:

$08 / 31 / 2014$

Company Size:

Small business ( $<500$ employees)

\section{Summary}

The ORNL Manufacturing Demonstration Facility (MDF) collaborated with Tru-Design to test the quality and durability of molds used for making fiber reinforced composites using additive manufacturing. The partners developed surface treatment techniques including epoxy coatings and machining to improve the quality of the surface finish. Test samples made using the printed and surface finished molds demonstrated life spans suitable for one-of-a-kind and low-volume applications, meeting the project objective.

\section{Background}

Fiber-reinforced composite (FRC) materials are in high demand because of their weight and energy saving potential for the automotive and aerospace industries. However, the manufacturing and design techniques of traditional composite molds, also called tools, limit the application of these materials, particularly in low volume and one-of-a-kind productions, due to the high labor cost and low rate of the production process. Molds for low-volume production are typically hand-made by a skilled technician, who makes each female tool from a male plug. This production process can require weeks of lead-time. In addition, the accuracy and design of the mold is limited by the technician's skill to replicate the male plug. One way to decrease tooling costs and increase design flexibility is to directly produce a mold with large scale additive manufacturing (AM).

Tru-Design is a small, Knoxville-based company with a background in the production of FRC materials and molds. The company provided expertise on mold designs, quality, and composite manufacturing procedures. One of the initial challenges for AM printed composite tools was to create a large tool with a smooth surface. Parts that are printed on the Big Area Additive Manufacturing system (BAAM) at the Manufacturing Demonstration Facility normally have a rough surface that is caused by the ridges where each printed layer intersects the part surface (Figure 1).

1 Research sponsored by the U.S. Department of Energy, Office of Energy Efficiency and Renewable Energy, Advanced Manufacturing Office, under contract DE-AC05-00OR22725 with UT-Battelle, LLC 


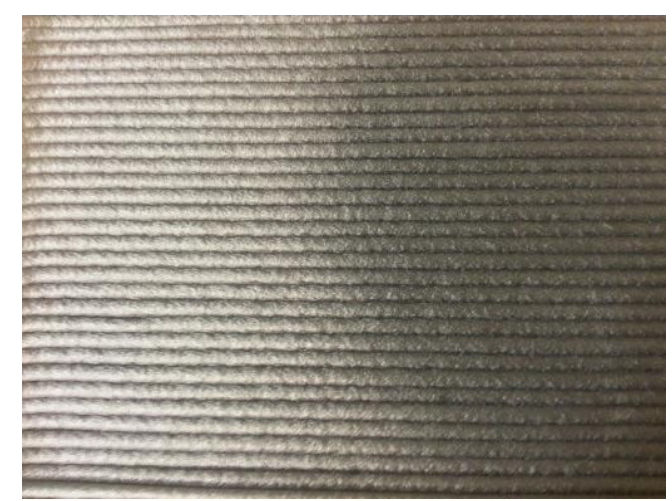

Figure 1. Ridges of a part printed on BAAM.

Elimination of the rough surface of BAAM parts was addressed by examining the durability of surface treatments using epoxy coatings and machining. The success metric of the project was the ability to identify treatments that resulted in an acceptable surface quality of the tool, and to then demonstration of an acceptable lifespan for the treatment.

\section{$\underline{\text { Technical Results }}$}

Using the ORNL Big Area Additive Manufacturing (BAAM) system, ORNL printed two types of molds using carbon fiber reinforced ABS. Two identical, hexagonal molds with 4 inch by 6 inch surfaces were printed to test durability of various coatings on simple flat surfaces. In addition, two identical, 12 inch by 8 inch geometrically complex molds were printed to test the effect of machining molds with curves and sharp angles.

Surface Coatings: To achieve an acceptable surface quality on the composite part, the printed surfaces of the hexagons were treated with a variety of coatings. Each surface on the first hexagon was coated in a different commercially available epoxy. Table 1 lists these coatings by manufacturer. The coatings on the second hexagon were identical to the first, but this mold was also treated with an adhesion promoter between the printed surface and the coating (Table 2). After the coatings were cured, they were sanded and polished.

Table 1. List of Surface Coatings on Hexagons

\begin{tabular}{|c|c|}
\hline Manufacturer & Product \\
\hline Valvoline PlioGrip & Plastic Repair 3 \\
\hline Valvoline PlioGrip & Finishing Cream \\
\hline Valvoline PlioGrip & Panel 60 \\
\hline Clausen & Z-Chrome Z-Glass \\
\hline $3 \mathrm{M}$ & EZ sand Flexible Parts Repair Adhesive \\
\hline $3 \mathrm{M}$ & Dent Filling Compound Body Filler \\
\hline
\end{tabular}

The molds were waxed with five coats of TR 104 High Temp releasing wax. Six plies of chopped mat fiberglass were cut to fit the molds. Then, Orca 555 vinyl ester resin was 
initiated with methyl ethyl ketone peroxide (MEKP). Because the purpose of these experiments was to determine the durability of the molds, the resin and MEKP were combined in a ratio that maximized the heat exerted by the exothermic reaction, while also retaining a workable pot-life. For this experiment, MEKP composed $5 \%$ of the total volume when mixed. The resin was brushed directly onto the mold, and between each layer of fiberglass mat. The parts cured on the mold until they reached room temperature, which took approximately one hour. After curing, the composite materials were pulled off the molds. The durability of the molds was then characterized by the number of parts pulled off the mold before visually significant surface damage occurred. All of the coatings on the hexagonal mold without adhesion promoter separated from the printed surface on the first pull. Pull tests on the hexagon coated using the adhesion promoter were more successful, with some coatings lasting up to four pulls, which is sufficient for some low volume or one-of-a-kind applications (Table 2).

Table 2. Results of Hexagonal Mold Trials

\begin{tabular}{|c|c|c|c|}
\hline Manufacturer & Product & Pulls & Failure Type \\
\hline Valvoline PlioGrip & Plastic Repair 3 & 4 & Adhesive \\
\hline Valvoline PlioGrip & Finishing Cream & 4 & Cohesive \\
\hline Valvoline PlioGrip & Panel 60 & 1 & Adhesive \\
\hline Clausen & Z-Chrome Z-Glass & 4 & Adhesive \\
\hline $3 \mathrm{M}$ & EZ sand Flexible Parts Repair Adhesive & 4 & Cohesive \\
\hline $3 \mathrm{M}$ & Dent Filling Compound Body Filler & 3 & Adhesive \\
\hline
\end{tabular}

The failure mode of coatings from the pull tests conducted on the hexagonal molds using the adhesion promoter was then characterized (Table 2). An adhesive failure is the de-bonding of one material from a different material. In these test, the epoxy coatings failed adhesively by completely pulling apart from printed surface. Cohesive failure is characterized by the de-bonding of a material from itself. During the pull tests, the coatings cohesively failed by having small portions of the coating pull apart from itself. This process left most of the epoxy on the surface, but the missing pieces caused a molding surface that was too rough for further FRC production.

Machining: To test the effect of build orientation on the machining of surfaces one complex mold was printed in a vertical orientation while the other was printed in a horizontal orientation. The geometrically complex molds (Figure 2) were given the shorthand name "shoe-shaped mold" because of their boot-like appearance.

The shoe-shaped molds were then CNC milled, and the machined surfaces were scanned with a FARO Arm 3-D scanner. No coatings were added to the machined molds. 


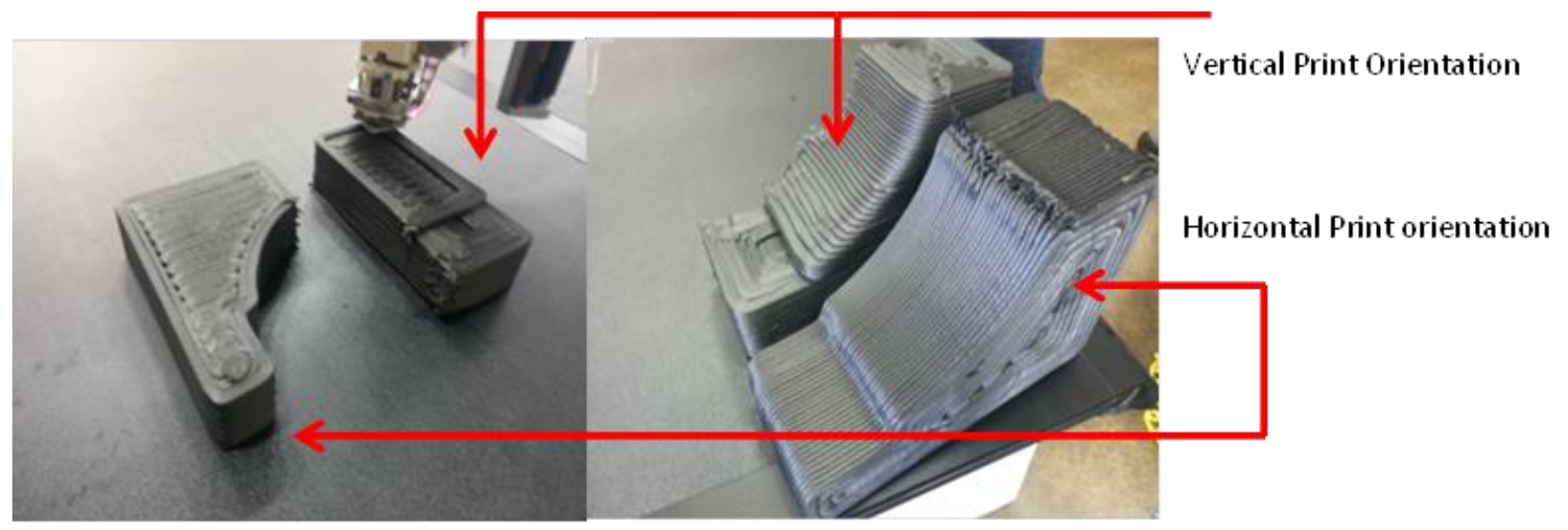

Figure 2. Printing of the "shoe-shaped molds (left) and completed molds (right).

Fiberglass reinforced composite materials were then hand-laid on the treated mold surfaces. After curing, the composite materials were then pulled off the molds. After the first pull on the machined molds, the pattern of the fiberglass mat was imprinted onto the machined surface (Figure 3). No difference in the surface finish or durability was noticed between the horizontal and vertical builds. The shoe molds each survived a total of five pulls before the surface was deemed too rough for production as determined by visual inspection, indicating that machining yields acceptable durability for one-of-a-kind and some low volume commercial applications.

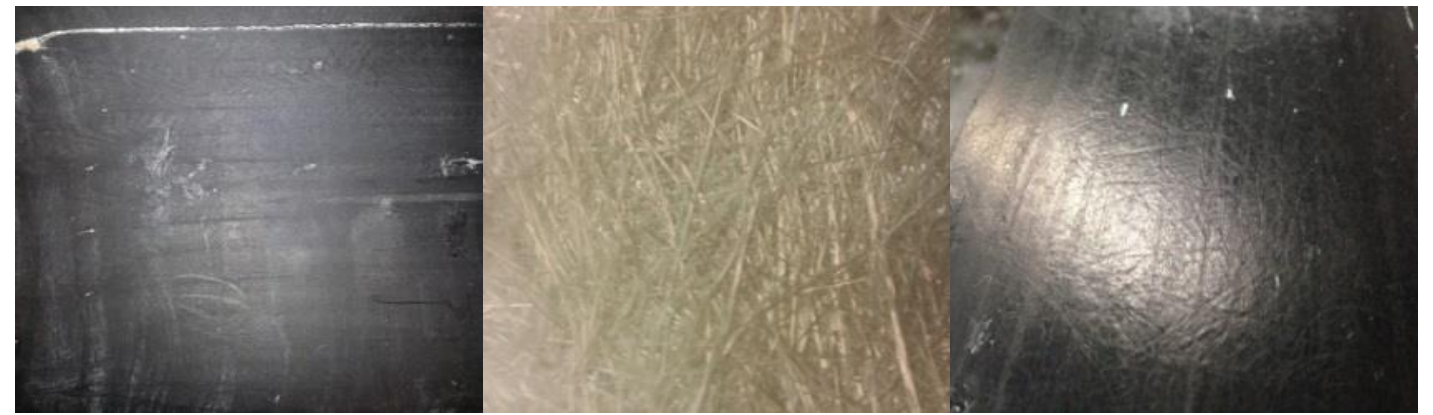

Figure 3. Machined surface of ABS-carbon fiber mold (left), pattern of fiberglass (middle), and imprint of pattern onto machined surface (right).

\section{$\underline{\text { Impacts }}$}

Rapid prototyping of functional and accurate parts has become vital to the success of competitive business practices. In order to secure contracts and funding, companies must produce highly representative prototypes. Traditionally, one-of-a-kind fiberreinforced molds are created for rapid prototypes, and the production of these molds can take weeks and is expensive. One of the largest areas of impact for AM is the reduction of labor, energy, and production time associated with developing a mold. By directly printing a mold on the Big Area Additive Manufacturing system, the production cycle of rapid prototyping a part is reduced by $50 \%$ to $70 \%$.

The results of this project demonstrated the benefits of additively manufacturing a mold for creating functional rapid prototypes. The printing and machining of the shoe-shaped mold took approximately one day to produce, which is significantly faster than traditional 
methods, which can take weeks. Additionally, the project demonstrated that this technology can be expanded into the market of low-volume productions of FRC materials. The shoe molds produced five composite parts before the surface deteriorated, and some of the epoxied surfaces produced four parts. However, surface finish still needs some improvement, and durability needs to be increased for other applications. Tru Design is moving forward toward commercialization of this technology by examining different machining methods and better surface coatings.

\section{Conclusions}

This project was successful in demonstrating two potential technologies for improving the commercial potential of large scale additively manufactured tools for the production of fiber-reinforced composite parts. The project objective was met by printing and examining a flat test panel and a geometrically complex tool. The hexagonal flat test panels were tested with coatings and an adhesion promoter while the shoe-shaped complex tool was tested with surface machining. Pull testing of the improved surfaces was performed to assess the durability of the tools. Four of the epoxy treatments survived four pulls, and the machined molds survived five pulls, establishing the potential for some low volume applications. However, the surface finish of the machined molds is still too rough for the intended commercial application. The next step for this technology is to examine the print feedstock material. Instead of using only carbon-fiber ABS, Tru-Design will compare the durability different printed polymers and fibers to the standard BAAM material.

\section{About the Company}

Tru-Design, LLC is creating, developing and manufacturing products using alternative materials, such as carbon fiber composites that will aid in conserving energy and natural resources for the benefit of our economy. Tru-Design is focused on engineering, prototyping and low-volume production of composite and carbon fiber products. The company's years of experience developing composite and carbon fiber manufacturing processes, position Tru-Design for manufacture and sales into several markets, but principally transportation markets. Tru-Design is a current participant of the Oak Ridge Carbon Fiber Composites Consortium.

\section{Points of Contact}

Chad Duty, ORNL, dutyc@ornl.gov, 865-574-5059

Robert Springfield, Tru-Design, rspringfield@trudesign.net, 865-279-9817 